\title{
METODOLOGIA ATIVA NA EDUCAÇÃO: Ensino, Pesquisa e Serviços
}

\author{
ACTIVE METHOD IN EDUCATion: Teaching, Researching and Services
}

\section{METODOLOGÍA ACTIVA EN EDUCACIÓN: Docencia, Investigación y}

\author{
Servicios
}

\author{
Leila Maria Vieira Kim \\ Paulo/SP - Brasil \\ ORCID: 0000-0003-4814-7557 \\ e-mail: leilakim.animus@gmail.com
}

Universidade de São Paulo, Instituto de Psicologia, Departamento de Psicologia Clínica - São

Palavras-chave: métodos ativos, interdisciplinaridade, multidisciplinaridade, intervenção educacional, pensamento

O Suplemento/2019 em Educação foi uma iniciativa de Heloisa Fleury, editora da Revista Brasileira de Psicodrama (RBP). Ela me contatou em meados de 2018, quando eu estava organizando um livro sobre Metodologia Ativa na Educação, para juntas, realizarmos o volume 27, número 1, da RBP, um passo além de editarmos um e-book, em Portugal.

Cientes da importância de novos rumos na Educação, compusemos o suplemento com autores que trabalham com metodologias ativas fundamentadas em diferentes abordagens teóricas, de todas as regiões do Brasil. Convidamos novos pareceristas do meio acadêmico internacional para ampliarmos a capacitação da equipe e incentivarmos a internacionalização de boas práticas editoriais em diferentes nichos. Portanto, este suplemento oportunizou novos investimentos com valor de notícia em publicações científicas com acesso aberto, em linguagem trilíngue, para atingir mais indivíduos e cooperar no movimento de renovação do psicodrama socioeducacional.

Mantivemos o layout da RBP na produção dos artigos originais, das comunicações breves e das resenhas que compõem este número, mas ampliamos a ideia de campo vincular no contato com o movimento dialético de intersubjetividade presente nesse momento de encontro (Moreno, 1993), conforme proposto pelas metodologias ativas na perspectiva de grupos interligados em redes autossustentáveis. Em outras palavras, esta produção científica possibilitou a socialização 
de propostas de vinculação social desenvolvidas por meio de projetos de intervenção educacional para construir ações, saberes, saber-fazer e ser, na promoção da saúde coletiva. Os métodos ativos vêm se desenvolvendo gradualmente desde o início do século passado, na articulação entre as ciências da educação e da saúde coletiva, em algumas universidades brasileiras. Propõem que docentes de diferentes áreas do conhecimento construam conteúdos comuns em sala de aula e os amplie com gestores e profissionais que atuem nos serviços à comunidade, por meio dos estágios supervisionados em ambos os campos, possibilitando assim a criação de novas pesquisas. Essa ideia de circularização entre grupos vem se expandindo na contemporaneidade e se apoia em duas vertentes: as de que todo conhecimento provém da prática social e a ela retorna e de que o conhecimento é um empreendimento coletivo. Portanto, viver a metodologia ativa implica sermos pouco a pouco modificados em nosso jeito de viver, de ver o outro e de nos posicionarmos em nosso mundo individual, social e profissional. Assumi-la, neste suplemento, nos vincula ao postulado de que "a educação tem um caráter permanente em razão da inconclusão dos homens e do devenir da realidade social que se materializa a cada momento" (Kim, 2018, p. 34). E de que a formação grupal continuada de docentes e gestores no trabalho integrativo ensino-aprendizagem-serviço, em ações estratégicas interdisciplinares integradas em um eixo multidisciplinar, estimula o protagonismo do aprendente na construção coletiva do conhecimento.

Para a constituição deste suplemento, analisamos as tendências e as perspectivas da educação no século XXI, direcionadas por questões básicas como: 1) Será que existem mudanças no novo paradigma que rompe com a tradição tecnicista fragmentária, por meio de uma formação sólida que transcenda as especializações, mediante a interdisciplinaridade e a indissociabilidade entre ensino, pesquisa e serviços à comunidade, com trabalho de conclusão de curso no final da formação?; 2) Como proporcionar um campo de produção simbólica e cultural para a criação de sentidos, significados e resolução de conflitos, que construa um pensamento crítico e possibilite a emancipação do sujeito?; 3) A avaliação e a retroalimentação dos processos de pesquisa derivados de interesses, necessidades e pré-ocupações investigativas de diferentes áreas de conhecimento, geram aspirações e saberes que lhes são próprios?

As informações contidas nas publicações a seguir sintetizadas podem funcionar como forma estratégica de construção de nosso jeito de pensar nosso próprio pensamento sobre as questões relacionadas anteriormente.

A resistência política ao ensino tradicional apontada pela contribuição de Maria da Penha Nery e Júlia Villela Teixeira Gisler. No artigo original "Sociodrama: método ativo na pesquisa, no ensino e na intervenção educacional", as autoras desvelam o diálogo empático estabelecido entre instituições e o poder na sociedade, pelo manejo de conflitos, permitindo assim a expansão da criatividade no contexto sociocultural. E na comunicação breve "Método educacional psicodramático como metodologia ativa no contexto do estágio supervisionado", Maisa Helena Altarugio mostra como a forma lúdica de ensino no curso de licenciatura em Química possibilita a reflexão de conflitos entre professores e estagiários. Desse modo, essas três autoras descrevem como os métodos ativos, como aprendizagem-serviço, integram práticas sociodramáticas ao conteúdo programático incorporado ao currículo e aplicam os saberes assim construídos, na busca de solução de situações-problema dos sujeitos participantes. 
Nessa mesma direção, percebemos a aplicação da pedagogia psicodramática como recurso didático em sala de aula, nos cursos de formação de psicodramatistas. $\mathrm{O}$ artigo original de Terezinha Tomé Baptista intitulado "Jogos Psicodramáticos no processo ensino-aprendizagem" demonstra como o método ativo opera e seus efeitos na qualidade de respostas e ampliação da capacidade perceptiva, nas inter-relações: aprendiz-aprendiz, aprendiz-professor e aprendizaprendizagem. Nessa mesma senda, a comunicação breve de Alexandra Sombrio Cardoso e Ellen Lamberg Carneiro Bond mostra "A pedagogia psicodramática como um método facilitador na escolha do tema monográfico", para a constituição de trabalhos de conclusão de curso no final da formação.

Outros serviços realizados fora do ambiente escolar são propostos por Simone Araújo Nicastro e Sonia Lisboa Ribeiro na orientação de pais analisada no artigo original "A transmissão psíquica do medo e sua rematrização pelo método ativo", que articula o psicodrama e a psicanálise por meio de objetos intermediários, para retratar a família como um sistema aberto para a transmissão e a instalação do medo em pacientes identificados.

Em nosso itinerário teórico sobre a aplicação dos métodos ativos na prática, artigos originais retratam pesquisas realizadas em diferentes abordagens, com grupos de sujeitos de diversos contextos culturais e geográficos, como mecanismo de resistência para conferir um sentido pessoal e político na vida dos coparticipantes.

Marcos Bidart Carneiro Novaes, Joceli Regina Drummond e Andréa Claudia de Souza na "Pesquisa participante a serviço da emancipação e da ruptura de silêncios: uma experiência no Brasil", refletem sobre a experiência e a trajetória profissional de mulheres bordadeiras na periferia de São Paulo. Os autores estabelecem uma relação entre a pesquisa participante e o método sociodramático para a formação de um coletivo empreendedor que abre espaços comunicativos para superar silêncios e mobilizar a emancipação.

É nesse caminho que Marília Marino diferencia e localiza historicamente a pesquisaintervenção da pesquisa-ação, na "Investigação sociodramática em um ato: pedagogia social a serviço da juventude", em que constrói espaços sociais para o desenvolvimento pessoalprofissional de jovens vinculados ao "Programa Ação Jovem".

Para além das trajetórias performáticas, espaços são apropriados pela construção coletiva e transdisciplinar possibilitada pelo método inovador, que articula psicodrama e palhaçaria em grupos abertos, criado por Marília Meneghetti Bruhn, Lilian Rodrigues Cruz e Kim Ouakil Boscolo. Elas o sintetizam no artigo "Psicologia, palhaçaria e psicodrama: construção coletiva de aprendizados e intervenções".

Ana Maria Fonseca Zampieri, em um eixo multiprofissional, amplia o espaço de ação transdisciplinar articulando o sociodrama construtivista e a terapia EMDR (Eye Movement Desensitization and Reprocessing) na prevenção secundária de traumas pós-catastróficos. Ela analisa as narrativas de 200 adultos participantes de intervenções realizadas em 25 cidades de seis estados brasileiros, para demonstrar a eficácia desse trabalho na promoção da saúde mental. Dessa mesma forma, Ceres Maria Campolim Almeida propõe "Atos socionômicos: sobrevivência humana e ecologias por métodos ativos", em que fornece elementos básicos para 
a constituição de pesquisas futuras, em prevenção primária com ênfase em educação e saúde, para integrar as relações intrapessoais e socioambientais em diferentes espaços sociais.

No movimento dialético desse percurso, a comunicação breve intitulada "A importância dos grupos na reeducação da velhice”, de Algaides Rodrigues, Darlise dos Passos Gomes e Ândria Marins Correio, aponta o grupo de idosos, como um espaço privilegiado para o resgate da saúde e o exercício da cidadania, recuperando o novo na velhice. Ao mesmo tempo que Luiz Claudio Bido, no artigo original "Metodologias ativas nas demandas educacionais contemporâneas: uma discussão à luz dos processos constituintes da singularidade humana em Edith Stein", relaciona o desenvolvimento de habilidades socioemocionais e a educação por valores com a busca de humanização dos processos de aprendizagem, em universitários. O testemunho de valores revela possibilidades do antigo no novo, em articulações que podem se tornar coletivas e se expandirem em redes.

Para fornecer elementos para o novo no futuro imediato, Ricardo Zagallo Camargo, Manolita Correia Lima e Danilo Martins Torini apresentam o artigo original "Educação, mídia e internet: desafios e possibilidades a partir do conceito de letramento digital". Os autores discutem esse conceito para o desenvolvimento do uso crítico e informado dos meios digitais, na busca de integração entre educação e comunicação social, mediado pelos métodos ativos.

Fica assim o desafio de coconstrução dos interesses investigativos de uma ou mais áreas do conhecimento para alimentar ou retroalimentar o processo de pesquisa de novos pesquisadores, com aportes teóricos e metodológicos das ciências da educação e saúde coletiva, em uma realidade composta de multitarefas, limitação de tempo, gestão e reciclagem de equipes, na indústria do conhecimento acelerada pela tecnologia, na contemporaneidade.

Para isso, incluímos como alternativa a resenha realizada por Marieli Mezari Vitali sobre a obra "Estatística sem matemática para psicologia", de Dancey \& Reidy (2019); e a sintetizada por Vannúzia Leal Andrade Peres sobre o livro "Pesquisa qualitativa e subjetividade: os processos de construção da informação", de Rey (2005). Na primeira, os autores propiciam uma imersão completa no universo estatístico até para os menos familiarizados, conseguindo seu entendimento e sua aplicação na análise de dados, sem a necessidade de entender fórmulas e cálculos complexos. Na segunda, o autor imbuído do estudo da representação de elementos intersubjetivos explica sobre processos teórico-metodológicos que precisam ser conhecidos para se enfrentar a complexa tarefa de se produzir conhecimento sobre fenômenos humanos, de forma crítica e criativa.

Então, propomos uma reflexão sobre pesquisas quantitativas e qualitativas para verificarmos quanto a articulação entre as ciências da educação e saúde condiciona e determina a recuperação do prazer de aprender na inter-relação entre educador-educando. E se elas oferecem um modelo dialógico para compreender a interdependência e a sobreposição dos processos intra e interpsíquicos, por meio da aprendizagem pela experiência. E se nesse espaço potencial se possibilita o desenvolvimento da capacidade de pensar, senso crítico, autonomia, independência para colocar em prática a decisão e se emancipar. Processo educativo como prática social baseada na troca de saberes científico e popular. Em outras palavras, neste suplemento incentivamos a educação para o conhecimento com base nas pré-ocupações da população, e não na reprodução do conhecimento. Educação como promotora da democracia tendo a escola como 
indutora de desenvolvimento cultural, artístico, econômico e tecnológico adequado a todas as camadas da população brasileira.

Agradeço esse convite que me permitiu entrar em contato com a coragem na noção de cuidado, que ampliou possibilidades para autores, pareceristas, profissionais que finalizaram o longo processo de avaliação dos manuscritos (peer review), custeados pela Federação Brasileira de Psicodrama (Febrap), exceto nas traduções oferecidas pelos autores. Mas esse fluxo editorial interferiu principalmente em minha própria aprendizagem pela experiência, graças à generosidade de Heloisa Fleury, na qual contatei diferentes dimensões visualizadas nas publicações aqui desenvolvidas e que poderão ser verificadas por todos que permitam "que eu o ocupe, seus pensamentos, sua mente, já que não tenho outra voz para falar a não ser a sua . . . precisa se permitir pensar meus pensamentos e, então, nenhum de nós será capaz de reinvidicar o pensamento como sua criação exclusiva" (Ogden, 2003, p. XVII).

\section{REFERÊNCIAS}

Kim, L. M. V. (2018). Metodologias ativas de ensino: coconstrução subjetiva da capacidade de pensar o próprio pensamento em sala de aula. Rev. Bras. Psicodrama, 26(1), 31-40. doi: $10.15329 / 2318-0498.20180015$.

Moreno, J. L. (1993). Psicodrama. São Paulo, SP: Cultrix.

Ogden, T. (2003). Os sujeitos da psicanálise. São Paulo, SP: Casa do Psicólogo.

Leila Maria Vieira Kim Mestra em Psicologia da Educação pela Pontifícia Universidade de São Paulo (PUC-SP). Doutora em Psicologia Clínica pela Universidade de São Paulo (USP). Ph.D. em Educação pela Universidade Nove de Julho (UNINOVE) e Estudos Culturais pela Universidade de Aveiro - Portugal (UA). Professora convidada de cursos de pós-graduação e pesquisadora internacional da pela Universidade de Aveiro - Portugal (UA). Palestrante, consultora e psicoterapeuta psicodramatista com base analítica. Fone: 5511995539925. 